\title{
The Value of a Synthetic Model-based Training Lab to Increase Proficiency with Endoscopic Approaches to the Spine
}

\author{
Gregory Basil $^{1}$, G Damian Brusko ${ }^{1}$, Jordan Brooks ${ }^{2}$, Michael Y. Wang ${ }^{1}$ \\ 1. Neurological Surgery, University of Miami Miller School of Medicine, Miami, USA 2. Neurological Surgery, University \\ of Miami, Miami, USA
}

Corresponding author: G Damian Brusko, g.brusko@med.miami.edu

\begin{abstract}
Introduction: The learning curve associated with endoscopic approaches to the spine is well established. In this study, we present our endoscopic training methodology and discuss the concepts and rationale of laboratory training as it relates to improving comfort and skill with endoscopic techniques.
\end{abstract}

Materials and Methods: A three-part endoscopic training laboratory for neurosurgical trainees and attendings was organized at the University of Miami, which included a lecture, instrumentation demonstration, and both synthetic model and cadaveric practice sessions. Participants completed pre- and post-lab surveys gauging their comfort and competency in the transforaminal approach to the lumbar spine.

Results: There were a total of 22 participants, with eight completing the pre-lab survey and 10 completing the post-lab survey. Sixteen participants engaged in the lab practical, with six of these participants performing the transforaminal approach on both the model and the cadaver. An increase in comfort level was demonstrated on the post-lab survey (5.9/10) for the transforaminal approach as compared to the prelab survey (2.6/10). Additionally, participants found the training model to be an effective teaching aid for the transforaminal technique $(8.8 / 10)$.

Conclusions: We believe that our study demonstrates the utility of simulated model-based training for gaining comfort and proficiency with endoscopic approaches to the spine and introduces a safe, costeffective method of educating practitioners on novel endoscopic approaches.

Categories: Medical Education, Neurosurgery, Anatomy

Keywords: endoscopic spine surgery, transforaminal, neurosurgical training, spine surgery

\section{Introduction}

Received 02/24/2020

Review began 02/28/2020 Review ended 03/17/2020 Published 03/19/2020

(c) Copyright 2020 Basil et al. This is an open access article distributed under the terms of the Creative Commons Attribution License CC-BY 4.0., which permits unrestricted use, distribution, and reproduction in any medium, provided the original author and source are credited.

There has been significant progress in the development of endoscopic techniques to treat spinal pathology over the past few decades [1]. While these surgeries were initially limited to decompressive procedures, endoscopic-assisted fusion surgeries are now gaining increasing popularity [2-9]. These approaches offer the same benefit as traditional open approaches with reduced blood loss, decreased postoperative pain, and earlier discharge $[2,10,11]$. Nevertheless, the steep learning curve associated with these procedures has been well outlined in the literature and is likely one of the greatest barriers to more widespread acceptance of these techniques.

There have been various solutions for overcoming this learning curve including enhanced academic conferences, laboratory training, and early supervision [12-15]. Laboratory training for these approaches can take various forms, including traditional lectures, cadaveric sessions, and training model-based practice.

In this paper, we present our endoscopic training methodology for a laboratory-based session and discuss the concepts and rationale of model-based training as it relates to improving surgeon comfort and skill levels with endoscopic techniques.

\section{Materials And Methods}

An endoscopic training laboratory was organized at the University of Miami surgical lab center for neurosurgical residents, fellows, and attendings. This lab consisted of a three-part course designed to introduce the concepts of endoscopic spine surgery, familiarize participants with the techniques and instrumentation, and improve comfort and skill levels with the procedure.

First, a senior neurosurgical resident with extensive endoscopic training presented a formal lecture highlighting the key anatomic landmarks for an endoscopic transforaminal approach, with particular attention focusing on Kambin's triangle. Participants were encouraged to utilize several lumbar spine 
models during the lecture period in order to enhance their understanding of the spatial relationships between the boundaries of Kambin's triangle prior to practicing the approach. The appropriate surgical technique for performing an endoscopic transforaminal approach to the lumbar spine was also reviewed in detail.

Next, participants were brought to the lab for a brief introduction to the various instruments used in this procedure. For the purposes of this lab, we employed the Spinendos (München, Germany) endoscope and associated equipment. An industry representative was available in the lab to demonstrate proper use of each instrument. A senior faculty member experienced in endoscopic techniques demonstrated the transforaminal approach on a spine training model. For this lab, we utilized the MISSTRAINER, produced by Creaplast (Verton, France).

Following the demonstration, participants attempted a transforaminal approach on the training model. There was no formal time or attempts limit during the training model session, such that each participant practiced until he or she felt comfortable with needle localization of the neural foramen. Following successful foraminal localization, the spine models were replaced with cadaveric specimens, and the same exercise was repeated.

In order to simulate as realistic a surgical experience as possible, an experienced X-ray technician performed fluoroscopy throughout the lab session, and the surgical scrub technician used in all endoscopic cases assisted the participants as well. Additionally, participants were asked to voluntarily complete a pre- and post-lab survey (Figures 1,2) designed to gauge their subjective pre- and post-lab knowledge and technical comfort level.

Question 1: Please select your PGY year.

$\begin{array}{llllllll}1 & 2 & 3 & 4 & 5 & 6 & 7 & \text { Attending }\end{array}$

Question 2: Approximately how many endoscopic spine cases have you participated in?

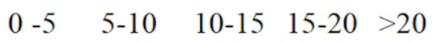

Question 3: Rate your comfort performing a transforaminal endoscopic approach independently.

Not comfortable at all

Extremely comfortable

$\begin{array}{llllllllll}1 & 2 & 3 & 4 & 5 & 6 & 7 & 8 & 9 & 10\end{array}$

Question 4: Rate your comfort performing an interlaminar endoscopic approach independently.

Not comfortable at all

Extremely comfortable

$\begin{array}{llllllllll}1 & 2 & 3 & 4 & 5 & 6 & 7 & 8 & 9 & 10\end{array}$

Question 5: Select your area of subspecialty neurosurgical interest.

Cranial Spine Both

Question 6: Do you plan on performing endoscopic spine surgery as a part of your practice going forward?

Yes No

FIGURE 1: Pre-lab survey.

PGY: postgraduate year. 


\section{Cureus}

Question 1: $\quad$ Please select your PGY year.

$\begin{array}{llllllll}1 & 2 & 3 & 4 & 5 & 6 & 7 & \text { Attending }\end{array}$

Question 2: Approximately how many endoscopic spine cases have you participated in?

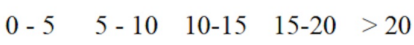

Question 3: Rate your comfort performing a transforaminal endoscopic approach independently after this lab.

\begin{tabular}{ccccccccccc} 
Not comfortable at all & & & & & \multicolumn{2}{c}{ Extremely comfortable } \\
1 & 2 & 3 & 4 & 5 & 6 & 7 & 8 & 9 & 10
\end{tabular}

Question 4: Rate your comfort performing an interlaminar endoscopic approach independently after this lab.
Not comfortable at all
2
$4 \quad 5$
$6 \quad 7$
Extremely comfortable

Question 5: Did you find this lab to be useful in learning how to perform a transforaminal endoscopic approach?
Not useful at all
2
3
4
6
$7 \quad 8 \quad$ Very useful

Question 6: Did you find this lab to be useful in learning how to perform an interlaminar endoscopic approach?

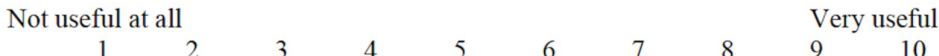

Question 7: Did you feel that the training model aided in your ability to appropriately localize for the transforaminal approach?

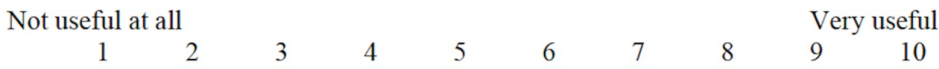

Question 8: Did you feel that the training model aided in your ability to appropriately localize for the interlaminar approach?
Not useful at all
1
$3 \quad 4$
5
$\begin{array}{llll}6 & 7 & & \text { Very useful }\end{array}$

Question 9: Do you plan on performing endoscopic spine surgery as a part of your practice going forward?

Yes No

Comments/Suggestions:

FIGURE 2: Post-lab survey.

PGY: postgraduate year.

\section{Results}

There were a total of 22 participants, with two attendings and one fellow, during the lecture period (Table 1). Sixteen of these participants engaged in the lab practical session, with six performing the transforaminal approach on both the model and the cadaver. 


\section{Cureus}

\section{Variable}

Postgraduate year 1

Postgraduate year 2

$1(6.7 \%)$

Postgraduate year 3

Postgraduate year 4

Postgraduate year 5

Postgraduate year 6

Postgraduate year 7

Spine fellow

Attending physician

Training type, N (\%)

Training model

Cadaver

Surgical approach, N (\%)

Transforaminal

Previous experience, N (\%)

No experience

Experience

Anterior posterior X-ray images, mean (SD)

Lateral X-ray images, mean (SD)

Total X-ray images, mean (SD)

Time to reach surgical target, seconds, mean (SD)

329.7 (137.7)

Disk space entered, $\mathrm{N}(\%)$

No

$13(59.1 \%)$

Yes

Total radiation dosage, $\mathrm{mSV}$, mean (SD)
$29.3(11.9)$

TABLE 1: Baseline demographic characteristic of participants who completed the endoscope spinal training lab.

$\mathrm{N}$ : number of participants; SD: standard deviation; mSV: millisieverts.

Eight participants completed the pre-lab survey and 10 completed the post-lab survey. Of the eight participants who completed the pre-lab survey, four indicated spine, two indicated cranial, and two indicated "both" as their subspecialty interest. Six participants affirmed a future interest in employing endoscopic procedures as part of their practice. The average comfort level was assessed with the pre-lab survey on a scale from 1 (not comfortable at all) to 10 (extremely comfortable) for general fluoroscopic localization (5.9/10) and the transforaminal approach (2.6/10) to the lumbar spine. An increase in comfort level was demonstrated on the post-lab survey, as average comfort increased to 5.9/10 for the transforaminal approach (Table 2). 


\section{Cureus}

\begin{tabular}{|l|l|l|l|}
\hline Characteristic & Pre-training & Post-training & P-value \\
\hline Comfort with transforaminal approach, mean (SD) & $n=8$ & $n=10$ & 0.0031 \\
\hline
\end{tabular}

TABLE 2: Self-reported physician comfort level pre-training compared to post-training for endoscopic approach.

Measured using a 10-point Likert scale with 1 being the least comfortable and 10 being the most comfortable.

SD: standard deviation.

Course participants rated the usefulness of cadaveric practice in teaching the transforaminal approach as $9 / 10$ on average. Similarly, participants found the training model to be an effective teaching aid for the transforaminal technique (8.8/10). Complete results from the pre- and post-lab surveys can be found in Tables 3, 4, respectively. 


\section{Cureus}

Variable/question

Participants

$n=8$

Postgraduate year, N (\%)

Postgraduate year 1

$2(25 \%)$

Postgraduate year 2

$0(0 \%)$

Postgraduate year 3

$1(12.5 \%)$

Postgraduate year 4

$1(12.5 \%)$

Postgraduate year 5

1 (12.5\%)

Postgraduate year 6

$2(25 \%)$

Postgraduate year 7

$1(12.5 \%)$

Previous endoscopic spine cases, N (\%)

$0-5$ cases

$7(87.5 \%)$

6-10 cases

$11-15$ cases

$1(12.5 \%)$

$16-20$ cases

$>20$ cases

Subset neurosurgical interest, $\mathrm{N}(\%)$

Cranial surgery

Spinal surgery

Both

$2(25 \%)$

Plans to practice endoscope surgery in future, $\mathrm{N}(\%)$

No

Yes

$6(75 \%)$

Comfort level with using fluoroscopy for lumbar spine surgery, mean (SD)

Comfort level with transforaminal approach independently, mean (SD)

$2.6(2.3)$

TABLE 3: Pre-lab survey responses.

SD: standard deviation. 


\section{Cureus}

\begin{tabular}{|c|c|}
\hline \multirow{2}{*}{ Variable/question } & Participants \\
\hline & $n=10$ \\
\hline \multicolumn{2}{|l|}{ Postgraduate year, $\mathrm{N}(\%)$} \\
\hline Postgraduate year 1 & $1(10 \%)$ \\
\hline Postgraduate year 2 & - \\
\hline Postgraduate year 3 & - \\
\hline Postgraduate year 4 & $1(10 \%)$ \\
\hline Postgraduate year 5 & $4(40 \%)$ \\
\hline Postgraduate year 6 & $1(10 \%)$ \\
\hline Postgraduate year 7 & $1(10 \%)$ \\
\hline \multicolumn{2}{|l|}{ Previous endoscopic spine cases, $\mathrm{N}(\%)$} \\
\hline $0-5$ cases & $8(80 \%)$ \\
\hline 6-10 cases & - \\
\hline $11-15$ cases & - \\
\hline 16-20 cases & $2(20 \%)$ \\
\hline$>20$ cases & - \\
\hline \multicolumn{2}{|l|}{ Plans to practice endoscope surgery in future, $\mathrm{N}(\%)$} \\
\hline No & $3(30 \%)$ \\
\hline Yes & $7(70 \%)$ \\
\hline Comfort level with transforaminal approach independently, mean (SD) & $5.9(1.7)$ \\
\hline Lab usefulness in learning transforaminal approach, mean (SD) & $9(1.0)$ \\
\hline Lab usefulness in localizing for the transforaminal approach, mean (SD) & $8.8(0.9)$ \\
\hline
\end{tabular}

\section{TABLE 4: Post-lab survey responses.}

SD: standard deviation.

\section{Discussion}

The learning curve associated with endoscopic approaches to the spine is a known challenge to more widespread adoption of these techniques $[12,13,16,17]$. Indeed, there have been several studies that show a steep decline in re-operations as the number of cases performed by the surgeon increases $[2,3,12,18,19]$. While the relatively rapid acquisition of proficiency in this technique is encouraging, it still poses a problem for the inexperienced practitioner. Needless to say, both the patient and surgeon would be well served if these techniques were refined in a practice setting, rather than in the operating room.

This concept of laboratory and simulated training is not new, nor is it novel to endoscopic spine surgery [2023]. A national survey of neurosurgery residency programs demonstrated that $95.4 \%$ of educators believed laboratory training was integral to training, yet only $50.8 \%$ of surveyed training sessions focused on endoscopy [23]. Yadav et al. described a number of pitfalls encountered in endoscopic spine surgery based on experiences of over 1,000 cases and discussed the importance of training mediums available to a young neurosurgeon in order to gain initial endoscopic proficiency [20]. Nevertheless, we were unable to find any literature that attempted to directly address or quantify the benefits of this approach to endoscopic spine surgery.

In the authors' opinion, one of the more difficult aspects to endoscopic spine surgery is the use of fluoroscopy for localization. While fluoroscopic localization is commonly used in any general spine practice, the level of difficulty and importance of precise fluoroscopic localization is increased with endoscopic surgery. This is especially true for the transforaminal approach where the endoscope is maneuvered into a 
very small opening and in close proximity to critical neural elements. Therefore, we focused the efforts of our study on gauging proficiency and comfort with this aspect of the procedure.

There was a statistically significant improvement in subjective surgeon comfort in performing the transforaminal approaches after our laboratory session. However, there was no statistically significant difference in the usefulness of the cadaver or synthetic model in terms of their efficacy as a training aid. We believe that this demonstrates the utility of either surgical training medium as a beneficial tool. Cadaveric specimens may limit the widespread adoption of similar training experiences due to their expense. Thus, it appears that more cost-effective training aids, such as synthetic spine models, may provide equal benefit in terms of improved comfort and skill levels, enabling greater ease in organizing training sessions.

There are undoubtedly shortcomings of this study. First and foremost is the small number of participants who performed the transforaminal approach on both the model and the cadaver. This was largely due to time constraints of residents and faculty, and the time-consuming nature of this procedure (especially in practitioners less familiar with this approach). However, while we fully acknowledge the small sample size of the study, we do believe that there are still meaningful takeaways, namely that trainees found the synthetic model-based tool to be a useful means of learning endoscopic approaches to the spine. We also fully recognize the subjective nature of the surveys conducted.

However, rather than using these data to suggest that all participants are fully proficient in endoscopic spine surgery after a single lab, or to suggest that we have definitely proven the value of a synthetic training model for endoscopic approaches to the spine, we do believe that our results suggest the need for further research in this critically important arena. Even with the small number of total participants, we do believe that it indicates a definite progression in knowledge and procedural competence of the lab participants. Furthermore, this study did not quantitatively assess technical parameters, such as localization time or number of fluoroscopic images taken. Measurement of these variables would likely have enhanced our conceptual argument that training models improved technical skill over time and future studies on similar training sessions should explore this relationship further. This study also did not address proficiency or comfort with the remaining components of the endoscopic transforaminal procedure such as complete discectomy and foraminotomy. Although these components were outside the scope of this study, we do believe that they would also be amenable to a simulated model-based training. Finally, while the training models are not perfect simulations, they offer relatively affordable and easy access to ongoing training which we believe will be invaluable to a new practitioner.

\section{Conclusions}

We believe that our study demonstrates the utility of simulated model-based training for gaining comfort and proficiency with endoscopic approaches to the spine. While further research is needed to fully quantify the benefits of these techniques and apply them to the all components of a full endoscopic decompression, we believe that this paper demonstrates a safe, cost-effective method of educating practitioners on novel endoscopic approaches.

\section{Additional Information \\ Disclosures}

Human subjects: Consent was obtained by all participants in this study. University of Miami IRB issued approval 20191125. The IRB determined this study meets the criteria for an exemption as described in Federal Regulation 45 CFR 46.104. This determination is effective on 11/21/2019. Animal subjects: All authors have confirmed that this study did not involve animal subjects or tissue. Conflicts of interest: In compliance with the ICMJE uniform disclosure form, all authors declare the following: Payment/services info: The training lab session, including training models and cadaveric specimens, were paid for by Flexible Spine, LLC. Financial relationships: Basil, Brusko, Brooks, Wang declare(s) Training Lab Funding from Flexible Spine, LLC. Provided funding for cadaveric specimens and training models. Wang declare(s) a grant from Department of Defense. Wang declare(s) personal fees and royalties from DePuy-Synthes Spine, Inc. Wang declare(s) royalties from Children's Hospital of Los Angeles. Wang declare(s) royalties from Springer Publishing. Wang declare(s) royalties from Quality Medical Publishing. Wang declare(s) personal fees from Stryker Spine. Wang declare(s) personal fees from K2M. Wang declare(s) personal fees from Spineology. Wang declare(s) Advisory Board Member from Vallum. Wang declare(s) stock/stock options from Spinicity. Wang declare(s) stock/stock options from Innovative Surgical Devices. Other relationships: All authors have declared that there are no other relationships or activities that could appear to have influenced the submitted work.

\section{References}

1. Choi G, Pophale CS, Patel B, Uniyal P: Endoscopic spine surgery. J Korean Neurosurg Soc. 2017, 60:485-497. 10.3340/jkns.2017.0203.004

2. Kolcun JPG, Brusko GD, Basil GW, Epstein R, Wang MY: Endoscopic transforaminal lumbar interbody fusion without general anesthesia: operative and clinical outcomes in 100 consecutive patients with a minimum 1year follow-up. Neurosurg Focus. 2019, 46:14-15. 10.3171/2018.12.FOCUS18701 
3. Anichini G, Landi A, Caporlingua F, et al.: Lumbar endoscopic microdiscectomy: where are we now? An updated literature review focused on clinical outcome, complications, and rate of recurrence. Biomed Res Int. 2015, 2015:1-14. 10.1155/2015/417801

4. Choi G, Lee SH, Raiturker PP, Lee S, Chae YS: Percutaneous endoscopic interlaminar discectomy for intracanalicular disc herniations at L5-S1 using a rigid working channel endoscope. Neurosurgery. 2006, 58:59-68. 10.1227/01.neu.0000192713.95921.4a

5. Ruetten S, Komp M, Godolias G: A new full-endoscopic technique for the interlaminar operation of lumbar disc herniations using 6-mm endoscopes: prospective 2-year results of 331 patients. Minim Invasive Neurosurg. 2006, 49:80-87. 10.1055/s-2006-932172

6. Ruetten S, Komp M, Merk H, Godolias G: Full-endoscopic interlaminar and transforaminal lumbar discectomy versus conventional microsurgical technique: a prospective, randomized, controlled study. Spine. 2008, 33:931-939. 10.1097/BRS.0b013e31816c8af7

7. Ruetten S, Komp M, Merk H, Godolias G: Use of newly developed instruments and endoscopes: fullendoscopic resection of lumbar disc herniations via the interlaminar and lateral transforaminal approach. J Neurosurg Spine. 2007, 6:521-530. 10.3171/spi.2007.6.6.2

8. Wang MY, Chang P, Grossman J: Development of an enhanced recovery after surgery (ERAS) approach for lumbar spinal fusion. J Neurosurg Spine. 2017, 26:411-418. 10.3171/2016.9.SPINE16375

9. Wang MY, Grossman J: Endoscopic minimally invasive transforaminal interbody fusion without general anesthesia: initial clinical experience with 1-year follow-up. Neurosurg Focus. 2016, 40:13-14. 10.3171/2015.11.FOCUS15435

10. Ahn Y, Youn MS, Heo DH: Endoscopic transforaminal lumbar interbody fusion: a comprehensive review . Expert Rev Med Devices. 2019, 16:373-380. 10.1080/17434440.2019.1610388

11. Yang Y, Liu ZY, Zhang LM, et al.: Microendoscopy-assisted minimally invasive versus open transforaminal lumbar interbody fusion for lumbar degenerative diseases: 5-year outcomes. World Neurosurg. 2018, 116:602-610. 10.1016/j.wneu.2018.05.049

12. Wang B, Lü G, Patel AA, Ren P, Cheng I: An evaluation of the learning curve for a complex surgical technique: the full endoscopic interlaminar approach for lumbar disc herniations. Spine J. 2011, 11:122-130. 10.1016/j.spinee.2010.12.006

13. Park SM, Kim HJ, Kim GU, et al.: Learning curve for lumbar decompressive laminectomy in biportal endoscopic spinal surgery using the cumulative summation test for learning curve. World Neurosurg. 2019, 122:1007-1013. 10.1016/j.wneu.2018.10.197

14. Sharif S, Afsar A: Learning curve and minimally invasive spine surgery. World Neurosurg. 2018, 119:472478. 10.1016/j.wneu.2018.06.094

15. Stienen MN, Smoll NR, Hildebrandt G, Schaller K, Gautschi OP: Early surgical education of residents is safe for microscopic lumbar disc surgery. Acta Neurochir. 2014, 156:1205-1214. 10.1007/s00701-014-2070-4

16. Choi DJ, Choi CM, Jung JT, Lee SJ, Kim YS: Learning curve associated with complications in biportal endoscopic spinal surgery: challenges and strategies. Asian Spine J. 2016, 10:624-629. 10.4184/asj.2016.10.4.624

17. Ghasem A, Sharma A, Greif DN, Alam M, Maaieh MA: The arrival of robotics in spine surgery: a review of the literature. Spine. 2018, 43:1670-1677. 10.1097/BRS.0000000000002695

18. Wang H, Zhou Y, Li C, Liu J, Xiang L: Risk factors for failure of single-level percutaneous endoscopic lumbar discectomy. J Neurosurg Spine. 2015, 23:320-325. 10.3171/2014.10.SPINE1442

19. Chaichankul C, Poopitaya S, Tassanawipas W: The effect of learning curve on the results of percutaneous transforaminal endoscopic lumbar discectomy. J Med Assoc Thai. 2012, 10:206-212.

20. Yadav YR, Lucano A, Ratre S, Parihar VS: Practical aspects and avoidance of complications in microendoscopic spine surgeries: a review. J Neurol Surg A Cent Eur Neurosurg. 2019, 80:291-301. 10.1055/s-0039-1677825

21. Davies J, Khatib M, Bello F: Open surgical simulation: a review. J Surg Educ. 2013, 70:618-627. 10.1016/j.jsurg.2013.04.007

22. Evans CH, Schenarts KD: Evolving educational techniques in surgical training. Surg Clin North Am. 2016, 96:71-88. 10.1016/j.suc.2015.09.005

23. Kshettry VR, Mullin JP, Schlenk R, Recinos PF, Benzel EC: The role of laboratory dissection training in neurosurgical residency: results of a national survey. World Neurosurg. 2014, 82:554-559. 10.1016/j.wneu.2014.05.028 